\section{O "cabo de força" da assistência: concepção e prática de psicólogos sobre o Apoio Matricial no Núcleo de Apoio à Saúde da Família}

\author{
The "tug of war" in healthcare: psychologists' \\ conception and practice concerning Matrix-Based \\ Support in the Center for Family Health Support \\ El "cable de alimentación" de la asistencia: \\ concepción y práctica de psicólogos sobre el \\ Apoyo Matricial en el Núcleo de Apoyo a la Salud \\ de la Familia
}

\section{Resumo}

O presente estudo analisou a concepção e a prática do matriciamento realizadas por psicólogos que trabalham no Núcleo de Apoio à Saúde da Família (NASF) no Município de São Paulo, Brasil. Foi utilizada a metodologia qualitativa, foram realizadas entrevistas semiestruturadas, gravadas e transcritas, submetidas à análise de conteúdo do tipo temática. Essa pesquisa demonstra dilemas entre a prescrição do trabalho e o que é possível ser realizado na prática, e entre a idealização da proposta colaborativa e sua implantação. A troca de saberes e a capacitação apareceram como principais significados da concepção de matriciamento. A prática revelou um contexto complexo com uma organização de trabalho bastante heterogênea com falta de articulação entre gerências e tensões na execução do trabalho compartilhado, como a divisão desigual de tarefas, em que as equipes de saúde da família devem se responsabilizar pela assistência direta à população enquanto o NASF ocupa o lugar daquele que capacita e supervisiona, gerando conflitos sobre de quem é a responsabilidade da assistência, constituindo um contexto pouco propicio ao cuidado integral, compartilhado e colaborativo.

Atenção Primária à Saúde; Psicologia; Saúde Mental;

Equipe de Assistência ao Paciente
Ana Paula Klein 1

Ana Flávia Pires Lucas d'Oliveira 1

doi: 10.1590/0102-311X00158815

\author{
Correspondência \\ A. P. Klein \\ Departamento de Medicina Preventiva, Faculdade de Medicina, \\ Universidade de São Paulo. \\ Av. Dr. Arnaldo 455, São Paulo, SP 01246-903, Brasil. \\ apk@usp.br \\ 1 Faculdade de Medicina, Universidade de São Paulo \\ São Paulo, Brasil.
}




\section{Introdução}

Este artigo tem como objetivo analisar a concepção e a prática da atividade de matriciamento para as equipes de saúde da família realizadas por psicólogos que trabalham nos Núcleos de Apoio à Saúde da Família (NASF) no Município de São Paulo, Brasil 1.

Os NASF são implantados no Brasil desde 2008 1, a fim de qualificar e ampliar a atuação da Estratégia Saúde da Família (ESF). A proposta fundamental desses núcleos visa à corresponsabilização das ações e o compartilhamento de decisões e condutas entre ESF e NASF para aumentar a resolubilidade dos casos na atenção primária à saúde e, idealmente, reduzir os encaminhamentos a serviços de atenção especializada, com maior longitudinalidade e integração dos profissionais no cuidado.

O NASF trabalha com a metodologia do Apoio Matricial (conhecido, na prática, como matriciamento) preconizada por Campos ${ }^{2}$, que propõe a construção de uma relação horizontal entre os profissionais, buscando reverter, assim, a lógica dominante da verticalidade da especialização que realiza procedimentos de forma isolada, fragmentada e não integrada com a equipe da atenção primária à saúde.

A organização em Estrutura Matricial nasceu baseada em proposta da área da administração devido à sofisticação das indústrias e à aceleração do desenvolvimento. A indústria aeroespacial, com a finalidade de promover alto grau de especialização e máxima eficiência nas operações, elaborou a Estrutura Matricial, que sugere o trabalho por projetos. Essa organização recomenda que os profissionais não trabalhem por departamentos, mas por projetos específicos, de forma não hierarquizada, de acordo com as habilidades necessárias à execução da tarefa por tempo determinado e conforme o cronograma estabelecido 3,4 .

Campos 2, baseado nessa proposta, sugere um novo arranjo organizacional para o trabalho em saúde, que se deseja horizontal e compartilhado. A proposta do trabalho por Apoio Matricial objetiva ampliar e fortalecer o escopo de ações dos profissionais da atenção primária à saúde pelo apoio de profissionais de diferentes profissões com o intuito de promover cogestão 5 .

Para estudar a relação entre profissionais de diferentes ocupações e saberes, lança-se mão das noções de campo de competência e núcleo de competência 6 a fim de contribuir com a reflexão sobre responsabilidades e atuações dos psicólogos dos NASF e da ESF. O campo refere-se a um conjunto de saberes e práticas ampliado, que interage com diferentes profissões ou especialidades de uma profissão, com limites imprecisos de atuação. Já o núcleo refere-se às especificidades e atribuições de uma especialidade/profissão, demarcando identidade do saber e da prática profissional 6,7. Neste trabalho, inspirado nessas noções, considera-se por analogia a atenção primária à saúde como análoga a um campo, ainda que referido especialmente à prática, e a psicologia como um núcleo de competência que busca atuar nesse campo, entre muitos outros.

Segundo os documentos do Ministério da Saúde e a literatura pesquisada, a equipe de apoio é responsável por oferecer suporte técnico-pedagógico e assistencial às equipes de referência 2,8,9, as quais devem se responsabilizar pelo acompanhamento dos casos, ampliando o olhar sobre os problemas de saúde, intensificando o vínculo com o paciente e garantindo a longitudinalidade do cuidado. A troca de saber, em que o conhecimento do especialista deixa de ser imposto vertical, fragmentado e hierarquicamente, passa a ser o objetivo almejado. O cuidado, antes baseado na autoridade do especialista, transforma-se em procedimentos dialógicos 9 .

Há diversas experiências sobre a aproximação de equipes de saúde mental da atenção primária à saúde. Em 1998, no Município de São Paulo, um grupo de psicólogas e uma assistente social iniciaram um trabalho conjunto com as equipes do Programa Saúde da Família (PSF), com o objetivo de ampliar a escuta dos profissionais e construir novos dispositivos de cuidado em saúde mental 10. Sem a utilização do termo Apoio Matricial, essas equipes volantes atuaram em busca de novas formas de gestão do cuidado.

Com a intenção de aproximar os profissionais de saúde mental da atenção primária à saúde, o Ministério da Saúde publica, em 2003, proposta de Apoio Matricial dos Centros de Atenção Psicossociais (CAPS) às equipes da atenção primária á saúde por meio de reuniões periódicas e disponibilidade para ações conjuntas. $\mathrm{O}$ documento sugere ainda que as equipes de saúde mental realizem ações de supervisão, atendimentos compartilhados e promovam capacitação às equipes 8 .

A diferença entre o matriciamento do CAPS e o do NASF se dá, sobretudo, pelo fato de o CAPS ser um serviço especializado, enquanto o NASF é um núcleo de apoio que não se caracteriza como 
um serviço em local fixo. O CAPS identifica quais são os casos de saúde mental graves e persistentes e os assume, responsabilizando-se pelo cuidado; já o NASF atua como uma retaguarda, porém, com pouca condição de assumir a assistência específica, deixando grande parte dos casos que apresentam sofrimento psíquico sob responsabilidade das equipes de saúde da família.

A demanda de saúde mental da atenção primária à saúde é diversa e complexa, uma vez que questões sociais, culturais e educacionais interferem nos cuidados à saúde. Casos com questões relativas a conflitos familiares, depressão, ansiedade, luto, queixas escolares, negligência no cuidado com crianças e ausência materna e paterna, violência de gênero, dependência química e transtornos alimentares são algumas das possíveis temáticas de discussão de caso entre ESF e NASF. A subjetividade implicada nessas questões nem sempre está associada a sintomas clínicos do campo da medicina e pode ser vista pelos profissionais da ESF como uma tarefa específica dos psicólogos e profissionais do campo da saúde mental.

Pinto et al. 11, em pesquisa sobre a avaliação da articulação das ações de saúde mental entre o CAPS e a ESF, identificaram que o matriciamento propicia estreitamento do laço entre os profissionais, possibilita práticas inovadoras e ampliação do trabalho multidisciplinar. Já Morais \& Tanaka 12, ao avaliarem os alcances e limites do Apoio Matricial de saúde mental na atenção primária à saúde, observaram que o acesso à equipe de apoio é restrito e não garante o cuidado integral das necessidades de saúde do indivíduo.

As experiências dos NASF revelam dificuldades na implantação do Apoio Matricial. Sampaio et al. 13, em pesquisa sobre o trabalho do NASF, identificaram fragilidades como o risco da reprodução do modelo assistencial individualizado e fragmentado, em virtude do modelo de gestão vigente no território, associado à imprecisão dos documentos ministeriais, e excesso de liberdade de cada equipe NASF em construir seu processo de trabalho. Lancman \& Barros 14, em pesquisa sobre a atuação dos terapeutas ocupacionais no NASF, observaram dificuldades como a diferença entre as agendas das equipes, ESF voltada para consultas individuais e NASF voltada para ações compartilhadas; excesso de demanda e carência de recursos, que pode pressionar o NASF para a atuação ambulatorial individualizada; gestão sob coordenação das Organizações Sociais de Saúde (OSS), que atuam de forma heterogênea, prejudicando a consolidação da política pública; e, por fim, a pouca experiência com trabalhos interdisciplinares, que favorece a atuação de forma isolada.

As diferentes experiências mostram obstáculos a serem superados na incorporação do Apoio Matricial no cotidiano do trabalho. Oliveira \& Campos 15 ressaltam que nesse processo é fundamental uma mudança nas relações de poder para que o Apoio Matricial possa ocorrer, enfatizando que a metodologia do apoio visa à cogestão e à construção democrática do cuidado.

O trabalho em equipe integrado, com heterogeneidade de profissionais e núcleos de saber, colocase como um desafio na prática diária, com tensões e possibilidades de encontros colaborativos.

\section{Metodologia}

Para a proposta deste estudo foi utilizada a abordagem qualitativa que permite "captar" a subjetividade dos sujeitos com os seus sistemas de valores, culturas, afetos, comportamentos e representações, proporcionando investigação mais aprofundada e compreensão dos sentidos que os profissionais identificam na própria atuação 16 .

No Município de São Paulo, de acordo com os dados publicados pela secretaria municipal de saúde, havia 87 equipes de NASF em atuação no período da coleta dos dados 17. Entretanto, não há informação oficial sobre o número de psicólogos que integram essas equipes devido às contratações estarem sob responsabilidade de diferentes OSS. Supõe-se que a grande maioria das equipes possua ao menos um psicólogo.

Para participação na pesquisa, foram convidados quinze psicólogos que atuam em equipes NASF de diferentes regiões do Município de São Paulo e pertencentes a diferentes OSS, a fim de garantir a investigação dos diversos contextos dos territórios da cidade. Como critério de inclusão à pesquisa, foram selecionados profissionais com período mínimo de um ano de atuação.

Foram realizadas entrevistas semiestruturadas com roteiro norteador elaborado pela pesquisadora para esta finalidade específica, com duração que variou de $1 \mathrm{~h} 15 \mathrm{~min}$ a $2 \mathrm{~h} 30 \mathrm{~min}$. O roteiro de 
entrevista foi composto dos seguintes tópicos: concepção, prática e organização do matriciamento; ações e atividades que os psicólogos desenvolvem; desenvolvimento de ações compartilhadas com outros profissionais e a relação que estabelecem com as equipes ESF e NASF; opiniões críticas acerca do trabalho do psicólogo em relação às possibilidades de atuação da profissão; e, por fim, buscou-se identificar as potências e os desafios do matriciamento.

Primeiramente, foram realizadas duas entrevistas pré-teste, com o objetivo de verificar se as perguntas estavam adequadas para alcançar os objetivos da pesquisa e realizar possíveis modificações, bem como verificar o tempo médio da entrevista. Após essa verificação, não foram feitas mudanças significativas no roteiro.

O trabalho de campo foi realizado no primeiro semestre de 2014. As entrevistas foram gravadas e transcritas, categorizadas e analisadas pela própria autora. Em um primeiro momento, na etapa da pré-análise, as entrevistas foram lidas até a impregnação, com o objetivo de se apreender a totalidade da fala dos entrevistados. Em seguida, houve a exploração do material. As entrevistas foram codificadas e categorizadas para sistematização do conjunto de informações expressas pelos entrevistados. Foram identificadas unidades de registro, por meio de falas e expressões significativas, para definição das categorias de análise. E, por fim, aconteceu o tratamento dos resultados, que consistiu na análise e na interpretação dos dados, correlacionando-os à literatura pesquisada.

Por ser um estudo com seres humanos, a pesquisa foi submetida e aprovada pelo Comitê de Ética em Pesquisa (CEP) da Faculdade de Medicina, Universidade de São Paulo (protocolo no 004/13) e pelo Comitê de Ética em Pesquisa da Secretaria Municipal de Saúde de São Paulo (parecer no 26/13). Todos os entrevistados assinaram o Termo de Consentimento Livre Esclarecido e foram comunicados sobre a possibilidade de haver interrupção da entrevista a qualquer momento, solicitação de esclarecimentos e sobre a preservação do sigilo.

\section{Resultados e discussão}

\section{Caracterização dos participantes}

Dos 15 participantes, seis eram do sexo masculino e nove do sexo feminino. Os integrantes graduaram-se entre 1980 e 2010, sendo 12 psicólogos graduados a partir de 2002. Apenas cinco profissionais tinham experiência anterior com atenção primária à saúde. O tempo de atuação no NASF variou de 1 ano e 6 meses a 5 anos e 4 meses: dois profissionais com até dois anos de atividade, oito atuando de dois a quatro anos, e cinco com mais de quatro anos de trabalho (três desses profissionais presentes desde a implantação, há mais de cinco anos). A diversidade de idade, ano de formação e interesse pelo trabalho chamou a atenção na caracterização dos participantes. A experiência anterior de trabalho na atenção primária à saúde não foi pré-requisito em suas contratações e a maioria dos entrevistados iniciou sua atuação em atenção primária à saúde com a entrada no NASF. Grande parte dos profissionais era jovem, com formação recente e com especialização na área da saúde. A maioria dos psicólogos apoiava duas ou três unidades básicas de saúde (UBS), com uma média de 10 a 14 equipes de saúde da família.

\section{Concepção de matriciamento}

Duas concepções apareceram de forma significativa nos relatos dos entrevistados: (1) a concepção do matriciamento como troca de saber e (2) a concepção do matriciamento como capacitação e supervisão. A troca de saber é enfatizada nos referenciais teóricos do Apoio Matricial como a possibilidade de construção do cuidado mais horizontal entre os profissionais, revertendo a lógica vertical das organizações de saúde 2. A ideia de troca, na qual saberes específicos podem ser incorporados por outros profissionais, é colocada por alguns psicólogos como o significado do termo matriciamento, visto como algo ideal e como objetivo a ser alcançado. Porém, muitos profissionais reconhecem a dificuldade de realizá-lo. Quando se referem à operação dessas trocas no trabalho, dificuldades aparecem. Há exemplos de trocas de saber bem-sucedidas da perspectiva dos entrevistados quando ambos os profissionais, do NASF e da ESF, aprendem uns com os outros. Alguns entrevistados citam como 
trocas com a ESF a possibilidade de o psicólogo aprender a ser mais objetivo, incluir, por exemplo, perguntas sobre alimentação e sono nas consultas e aprendizados sobre doenças prevalentes da atenção primária à saúde, como hipertensão e diabetes. No caso da ESF, os psicólogos relatam mudanças no olhar dos profissionais da equipes de saúde da família no reconhecimento da subjetividade e na desmitificação dos transtornos mentais. Contudo, verifica-se que muitos profissionais falam sobre o que ensinam e poucos falam sobre o que aprendem. A troca almejada apresenta-se geralmente como via de mão única, em que os profissionais do NASF ensinam a equipe de saúde da família, no entanto pouco percebem o conhecimento que a ESF pode lhes proporcionar.

Os entrevistados valorizam a troca de saber porque acreditam na proposta da horizontalidade entre os saberes e as profissões, mas, quando contam o que fazem, os elementos de troca pouco aparecem. Na verdade, os psicólogos percebem que as trocas ocorrem mais com os profissionais do NASF do que com a equipe de saúde da família, como expressou um entrevistado: "Compartilhado com a Estratégia, engraçado isso... né? A gente é apoio para a Estratégia e trabalha mais com o NASF, é isso mesmo. Com a Estratégia a gente faz pouca coisa, são poucos os trabalhos que a gente faz [juntos]” (E4).

$\mathrm{O}$ desejo de construir junto e trocar saberes expressa incorporação e adesão à proposta de horizontalidade. Todavia, simultaneamente há o desejo dos psicólogos de transmitir seus conhecimentos à equipe de saúde da família.

A ideia de capacitação e supervisão, entendida como passagem de conhecimento especializado, surge nos relatos de forma mais intensa e mais valorizada, apesar de os entrevistados evitarem o termo capacitação, mas reiterarem seu sentido.

"Então, antes, quando eu entrei, eu achei que seria uma coisa muito mais assistencialista, hoje eu acho que o meu maior papel é de ser matriciadora, sabe, de explicar, mesmo que seja explicar 200 mil vezes a mesma informação, mas acho que é isso de ensinar essas pessoas a trabalharem de uma forma, enfim..." (E6).

A intenção de capacitar e transmitir conhecimento unilateralmente é vista por muitos dos psicólogos como geradora de uma relação hierárquica, uma vez que um detém um saber que o outro precisa adquirir, gerando reações diversas quanto à sua aceitação. Oliveira 18, em estudo sobre as ações de saúde mental entre as equipes ESF e NASF, identificou uma postura dos profissionais do NASF de divisão entre "aqueles que sabem" - NASF - e "aqueles que devem aprender" - ESF. Em contrapartida, há psicólogos que identificam a existência dessa verticalidade nas relações, valoram negativamente quando isso acontece e desejam que haja transformação na concepção de capacitação.

"Acho que o modelo do NASF: eu sou o especialista e vou te ensinar a fazer e ensinar como resolver as coisas, eu espero que ele esteja falido, que ele não fique só nisso. Isso você pode chamar de educação permanente, e fazer uma aula, capacitar, ensinar todo mundo, e fazer educação bancária. E isso para mim é vazio, acho que só faz sentido se for uma intervenção junto, em parceria, e se for necessário fazer dentro de uma atuação pactuada, com atuação territorial, vai se fazer psicoterapia também" (E14).

É notável que o profissional reconhece que a construção de um trabalho compartilhado se realiza não só na intervenção conjunta (em que um profissional da ESF atende ao paciente em conjunto com um profissional do NASF), mas também na atuação pactuada nas reuniões de matriciamento e construção de projetos terapêuticos, que inclui também ações específicas dos núcleos de competência em que a clínica psicoterápica pode ser incluída (tema que se retomará ao falar das práticas do matriciamento). A proposta do arranjo matricial visa promover maior interação entre os profissionais, reconhecendo e valorizando justamente cada profissional de saúde como integrante do cuidado e das decisões sobre o cuidado, potencializando o poder de gestão da equipe interdisciplinar ${ }^{9}$. A identidade do profissional é preservada, ao mesmo tempo em que suas intervenções são ampliadas com ações interdisciplinares, comuns a todos 2 .

Há entre os entrevistados compreensões divergentes sobre a concepção de matriciamento e, portanto, da tarefa que o matriciador deve realizar. Em particular, foi detectada grande tensão quanto à assistência específica aos casos. Alguns profissionais entendem que a responsabilidade sobre a assistência não cabe a eles; outros defendem a necessidade de ofertar ações assistenciais específicas do psicólogo para o cuidado dos casos. Ver-se-á, na prática, como essas diferentes concepções se manifestam. 


\section{Prática de matriciamento}

As reuniões em que as equipes de saúde da família discutem casos com a equipe NASF são denominadas reuniões de matriciamento. Nessas reuniões, são discutidos casos, propostas de grupos, ações coletivas no território e articulações com outros serviços. As equipe NASF se organizam de forma muito variada. Existem arranjos em duplas ou trios em que dois ou três profissionais do NASF serão referência de um número de equipe saúde da família, entrarão nas reuniões regularmente e serão responsáveis pelo manejo dos casos. Outro arranjo possível são os núcleos temáticos, como saúde mental e reabilitação, ou saúde mental, saúde da mulher, saúde da criança e reabilitação. Os profissionais do NASF se dividem nesses núcleos para serem referência, de acordo com as profissões que consideram pertinentes a cada tema. E outro arranjo citado pelos entrevistados é a participação de todos os profissionais do NASF nas reuniões de matriciamento.

A divisão dos profissionais nesses arranjos se deu de acordo com a conveniência das equipe NASF e suas respectivas OSS, desconsiderando a presença de profissionais com o conhecimento necessário para o cuidado de cada caso e sem avaliações sobre as principais necessidades de saúde do território. A troca frequente de arranjos citada pelos profissionais expôs a dificuldade de compor as equipes para o matriciamento e o distanciamento da noção do matriciamento, que, por definição, deveria mobilizar os profissionais com o saber e a prática adequada a cada caso ${ }^{2}$. A heterogeneidade de profissões e as diversas áreas técnicas preconizadas para o trabalho de apoio tornam-se um desafio a ser superado no trabalho colaborativo e conjunto.

A tensão matriciamento $\mathrm{x}$ assistência específica se destacou na análise dos dados. Apesar da valorização da concepção de troca de saber, o Apoio Matricial é entendido majoritariamente como capacitar a equipe saúde da família para que ela se responsabilize pela demanda ou, no máximo, faça a intervenção de forma conjunta. Entende-se, aqui, que a troca de saberes pode ser uma divisão de tarefas em que cada especialidade tem um trabalho a executar, de acordo com a necessidade do caso e o saber necessário à intervenção, que deve ser realizada de forma articulada. $\mathrm{O}$ matriciamento acaba sendo entendido como restrito ao momento de discussão de caso, havendo, nesse momento, uma disputa por quem se responsabilizará pela assistência específica. Em razão de o matriciamento ser percebido pela maioria dos profissionais como composto da discussão do caso e, no máximo, de atendimentos compartilhados, quem atende sozinho com foco no seu núcleo de competência é visto como "traidor" da proposta do NASF. A possibilidade de intervenção específica de um técnico é vista por muitos psicólogos como descaracterização da proposta do Apoio Matricial e, portanto, rejeitada. Por outro lado, esse atendimento do "especialista” é uma demanda insistente das equipe saúde da família.

"Eu acho que eu atendi demais sozinho. Deveria ter atendido menos individualmente, menos especificamente, deveria ter batido um pouco mais o pé em alguns tipos de caso (...). Só que aí o quanto que eu consegui trazer de saúde mental para essa equipe, o quanto eu consegui adicionar de olhar para o olhar deles ficou comprometido. Teria feito um pouco diferente. Teria pensado em capacitações, mesmo com as equipes não pedindo muito, teria me aproximado mais das gerentes, seduzido, no bom sentido: 'Olha, vamos pensar nisso, isso vai se reverter em bom atendimento para os pacientes'. Sabe? Teria feito diferente, eu acho” (E9).

Em um contexto de falta de recursos para o cuidado do sofrimento mental e da dificuldade de acesso à atenção secundária 19,20, as equipes ESF e NASF iniciam uma disputa por quem será responsável pela assistência direta à população das questões relativas ao sofrimento psíquico. As equipes entram em um cabo de força para ver quem se responsabilizará pelo atendimento às pessoas: ora a ESF "ganha", ao conseguir uma consulta específica a ser feita pelo NASF, ora o NASF "ganha", ao conseguir que a ESF se responsabilize por uma intervenção que estava sendo demandada a ele.

Peduzzi 21 contribui para essa discussão ao definir que o trabalho em equipe não propõe extinguir as especificidades dos trabalhos, mas se constitui na coexistência de intervenções próprias de cada área e execução de ações comuns que podem ser praticadas por agentes de diferentes profissões. Uma equipe integração, como conceituado por ela, deveria ser capaz de ter um projeto assistencial comum, com ações parcelares de cada profissional, integradas em um mesmo projeto de trabalho.

A tensão da disputa pela não assistência se revela particularmente nas reuniões de matriciamento, momentos em que ocorrem as discussões de casos e são definidas condutas e propostas terapêuticas. Em tais encontros, os profissionais do NASF parecem ficar em constante batalha, reforçando seu caráter não ambulatorial, e as equipes saúde da família, pressionando e solicitando intervenções espe- 
cíficas por entenderem que a demanda de sofrimento mental tampouco cabe a elas. Na lógica em que o NASF foi implantado, as equipes dificilmente se alinharão, e as tensões e conflitos tendem a persistir.

"Você faz uma explanação do que é o NASF, qual a função, qual o papel, os profissionais que estão inseridos, de não tornar ambulatório, de não se realizar atendimentos individualizados, fazer mais num contexto de grupo. Aí na semana seguinte você volta para a mesma equipe e tem que falar de novo, porque eles têm uma resistência, por também serem cobrados a dar uma resolutividade, né? A resolutividade para alguns é atender paciente dentro de uma agenda do profissional, resolutividade para eles não é você estar discutindo caso, fazendo Projeto Terapêutico Singular (PTS), pensando em ações mais abrangentes, né? Encaminhar para um atendimento no Centro de Referência da Assistência Social (CRAS), isso não é resolutividade, resolutividade é estar ali apoiando, fazendo intervenção, fazendo a terapêutica, e não é isso, não é bem assim" (E8).

A maioria dos entrevistados compreende que o arranjo matricial propõe a realização de ações de forma conjunta, mas se queixa da dificuldade, pois as equipes de saúde da família não possuem horário para atividades compartilhadas. Alguns psicólogos atribuem a dificuldade para essa realização à resistência da ESF, desconsiderando um contexto complexo da atenção primária à saúde brasileira com excesso de demanda e sobrecarga de trabalho dos profissionais da ESF com metas altas de produção.

Chama a atenção o pouco compromisso de parte dos profissionais sobre quem prestará a assistência psicoterapêutica, já que quase não há serviços na rede assistencial pública dirigidos ao cuidado contínuo do sofrimento psíquico, que não é critério para o atendimento no CAPS, ficando o psicólogo do NASF entre poder/dever atender ou não. Em contrapartida, alguns psicólogos, preocupados e sensibilizados com a grande demanda de saúde mental, reconhecem a necessidade assistencial e se angustiam com a escassa rede de serviços. Alguns se disponibilizam para a assistência direta à população, todavia há o entendimento de que estão cobrindo uma demanda que não seria de sua responsabilidade. Outros sugerem a criação de ambulatórios de saúde mental para encaminhamentos, o que se entende que poderia resultar na fragmentação do cuidado, indo na contramão da proposta colaborativa. Contudo, mesmo os profissionais com empenho e responsabilidade de colaborar com os cuidados ao sofrimento psíquico, enfrentam dificuldades. Tendo um número grande de equipe de saúde da família e UBS para apoiar, a oferta assistencial dos psicólogos do NASF é insuficiente para abarcar a necessidade da população, e a articulação fica comprometida.

Outro fator que potencializa a desarticulação entre as equipes ESF e NASF é a existência de gestões diferentes. A equipe de saúde da família está sob responsabilidade do gestor da UBS, que pode ser gerida tanto por OSS como pela administração direta do município, com profissionais concursados, e o NASF está sob coordenação de um profissional designado exclusivamente à coordenação do NASF, que é sempre administrado por OSS no Município de São Paulo. Tal contexto é analisado como prejudicial pelos entrevistados, dado que conflitos e melindres podem ocorrer em virtude da diferença de objetivos porque a ESF tem sua agenda voltada a consultas individuais e o NASF tem uma agenda voltada majoritariamente a atividades coletivas e compartilhadas, das diferenças nas metas de produção, uma vez que a ESF tem sua produção contabilizada por número de consultas e visitas domiciliares, em uma lógica produtivista, enquanto o NASF tem metas por proporção de carga horária. Em regra, o NASF possui metas muito mais flexíveis e menor pressão de quantidade de consultas do que a ESF.

A falta de recurso especializado e adequado às necessidades da população remete à concepção da atenção primária à saúde seletiva, em que os serviços de saúde oferecidos apresentam baixa resolubilidade, com capacidade para enfrentar um número limitado de problemas e objetivos restritos 20 . Testa 22 (p. 162) já havia ressaltado que, em países sem uma rede de referência adequada, a atenção primária à saúde torna-se "atenção primitiva de saúde", pois a atenção primária à saúde não é apenas a porta de entrada, mas a única porta possível, em razão da falta de acesso aos especialistas. Tal contexto é um alerta para a necessidade de avaliações sobre os cuidados que o NASF oferta e sua efetividade, pois há grande parcela da população que está sem acesso às especialidades, corroborando com Azevedo \& Kind 23, que identificaram que o NASF não consegue absorver a demanda vinda da ESF, deixando muitos casos sem atendimento, e com Morais \& Tanaka 12 , que verificaram acesso restrito à equipe de apoio.

O excesso de demanda e a carência de recursos foram identificados por Campos \& Domitti ${ }^{9}$ como um obstáculo à proposta matricial. Ao mesmo tempo, os autores consideram que essa metodologia pode contribuir ao racionar o acesso aos especialistas e, consequentemente, potencializar as ações da atenção primária à saúde. As relações de poder de gestores, médicos e especialistas em relação aos 
profissionais da atenção primária à saúde também já haviam sido identificadas pelos autores ${ }^{9}$, que reforçam que o Apoio Matricial só é possível com a existência de espaços coletivos que propiciam a cogestão.

O desafio que se coloca aos psicólogos é como prestar assistência qualificada e integral sem reproduzir o modelo tradicional fragmentado da psicoterapia e sem negligenciar cuidados que exigem um olhar especializado. Existem casos que são pertinentes à atenção primária à saúde, porém não conseguem ser atendidos de forma resolutiva apenas pela equipe de saúde da família, seja por falta de saber específico, seja por questão de agenda/tempo. Nesses casos, que englobam sofrimentos psíquicos prevalentes, há de se construir uma modalidade de cuidado própria da saúde mental na atenção primária à saúde.

Para alcançar o objetivo principal da política 1, o aumento da resolubilidade da atenção primária à saúde, a relação entre as equipes ESF e NASF necessita de mudanças. A disputa pela assistência distancia as equipes, gerando desgaste entre os profissionais e possíveis prejuízos ao cuidado ofertado à população, uma vez que não há clareza sobre os responsáveis pela assistência e não há menção sobre a participação dos pacientes na elaboração dos projetos terapêuticos no relato dos entrevistados. A integração efetiva das equipes pode propiciar um cuidado mais integral, ao potencializar ações comuns a todos do campo da atenção primária à saúde e saúde coletiva, ao mesmo tempo em que garante a atuação dos núcleos de competência, produzindo, dessa forma, uma atenção primária à saúde de qualidade e mais efetiva. Para tanto, é fundamental ter maior clareza sobre a finalidade do Apoio Matricial, bem como definições e pactuações sobre as tarefas que cada profissional deve executar e a responsabilidade de todos no cuidado direto, evitando a divisão entre "os que pensam" e "os que fazem".

\section{Considerações finais}

A tensão matriciamento $\mathrm{x}$ assistência específica está relacionada à grande quantidade de pessoas com sofrimento mental, somada ao aumento de número de casos que o próprio Apoio Matricial gera com a visibilidade de demandas e necessidades antes não reconhecidas pelas equipes de saúde da família, aliada à falta de especialistas disponíveis para a assistência específica. Os obstáculos para a troca de saber se efetivar sobressaem nos relatos. A dificuldade do trabalho em equipe, a sobrecarga de atividade que as equipes de saúde da família vivenciam, as resistências da equipe de saúde da família em compartilhar e do NASF em prestar assistência também apareceram como barreira para a construção colaborativa das ações.

O reconhecimento de quais aspectos dizem respeito ao campo da atenção primária à saúde, que deveriam ser comuns a todos, e das especificidades dos núcleos de competência que serão de responsabilidade dos profissionais especialistas pode colaborar com a identificação de limites entre quais casos podem ser assumidos integralmente pela ESF e quais demandam intervenção específica de um profissional da saúde mental. Vale ressaltar que, por conta da complexidade dos casos, serão necessárias composições de trabalho em equipe criativas caso a caso para o cuidado da singularidade do sofrimento de cada paciente.

Esta pesquisa aponta dilemas entre a prescrição do trabalho e o que é possível ser realizado na prática, e entre a idealização da proposta colaborativa e sua implantação. A prática revelou um contexto complexo com uma organização de trabalho bastante heterogênea - com falta de articulação entre as gerências da ESF e do NASF e tensões na execução do trabalho compartilhado -, com sobrecarga de trabalho para a atenção primária à saúde - com excesso de demanda e metas difíceis de atingir por causa da falta de recursos humanos e equipamentos em número adequado - e tornou visível diferentes concepções sobre o matriciamento e a tarefa a ser realizada pelo NASF, constituindo um contexto pouco propício ao cuidado integral, compartilhado e colaborativo. No entanto, há grande potencialidade para o trabalho do psicólogo ser mais colaborativo e voltado para a atenção primária à saúde nas trocas que conseguem ser estabelecidas, nas atividades grupais criadas e na criatividade de repensar sua identidade profissional e os objetivos de seu trabalho na construção do SUS. 


\section{Colaboradores}

A. P. Klein participou da concepção da pesquisa, coleta dos dados, levantamento bibliográfico, metodologia, análise e interpretação dos dados, redação do artigo, e revisão final. A. F. P. L. d'Oliveira participou da concepção da pesquisa, metodologia, análise e interpretação dos dados.

\section{Referências}

1. Ministério da Saúde. Portaria no 154, de 24 de janeiro de 2008. Cria os Núcleos de Apoio à Saúde da Família - NASF. Diário Oficial da União 2008; 25 jan.

2. Campos GWS. Equipes de referência e apoio especializado matricial: um ensaio sobre a reorganização do trabalho em saúde. Ciênc Saúde Coletiva 1999; 4:393-403.

3. Lodi JB. A estrutura matricial e a estrutura sistêmica: dois novos tipos de organização. Revista de Administração de Empresas 1970; 10:157-9.

4. Motta FCP. Teoria geral da administração, uma introdução. 19ạ Ed. São Paulo: Livraria Pioneira Editora; 1995.

5. Cunha GT, Campos GWS. Apoio matricial e atenção primária em saúde. Saúde Soc 2011; 20: 961-70.

6. Campos GWS, Chakour M, Santos RC. Análise crítica sobre especialidades médicas e estratégias para integrá-las ao Sistema Único de Saúde (SUS). Cad Saúde Pública 1997; 13:141-4.

7. Campos GWS. Saúde pública e saúde coletiva: campo e núcleo de saberes e práticas. Ciênc Saúde Coletiva 2000; 5:219-50.

8. Coordenação de Saúde Mental/Coordenação de Gestão de Atenção Básica, Secretaria de Atenção Básica, Ministério da Saúde. Saúde mental e atenção básica: o vínculo e o diálogo necessários. Inclusão das ações de Saúde Mental na Atenção Básica. Circular conjunta no 01/03. http://portal. saude.gov.br/portal/arquivos/pdf/diretrizes.pdf (acessado 05/Jan/2013).

9. Campos GWS, Domitti AC. Apoio matricial e equipe de referência: uma metodologia para gestão do trabalho interdisciplinar em saúde. Cad Saúde Pública 2007; 23:399-407.

10. Lancetti A. Saúde mental nas entranhas da metrópole. In: Lancetti A, organizador. Saúde mental e saúde da família. São Paulo: Editora Hucitec; 2000. p. 11-52. (Saúde e Loucura, 7).

11. Pinto AGA, Jorge MSB, Vasconcelos MGF, Sampaio JJC, Lima GP, Bastos VC, et al. Apoio matricial como dispositivo do cuidado em saúde mental na atenção primária: olhares múltiplos e dispositivos para resolubilidade. Ciênc Saúde Coletiva 2012; 17:653-60.

12. Morais APP, Tanaka OY. Apoio matricial em saúde mental: alcances e limites na atenção básica. Saúde Soc 2012; 21:161-70.

13. Sampaio J, Sousa CSM, Marcolino EC, Magalhães FC, Souza FF, Rocha AMO, et al. O NASF como dispositivo da gestão: limites e possibilidades. Rev Bras Ciênc Saúde 2012; 16:317-24.

14. Lancman S, Barros JO. Estratégia de saúde da família (ESF), Núcleo de Apoio à Saúde da Família (NASF) e terapia ocupacional: problematizando as interfaces. Rev Ter Ocup 2011; 22:263-9.

15. Oliveira MM, Campos GWS. Apoio matricial e institucional: analisando suas construções. Ciênc Saúde Coletiva 2015; 20:229-38.

16. Bardin L. Análise de conteúdo. Lisboa: Edições 70; 2009. 
17. Secretaria de Saúde do Município de São Paulo. Estratégia Saúde da Família, 2012. http://www. prefeitura.sp.gov.br/cidade/secretarias/saude/ atencao_basica/esf (acessado em 12/Mai/2012).

18. Oliveira FRL. A integração das ações no campo da Saúde Mental entre a Estratégia de Saúde da Família e o Núcleo de Apoio à Saúde da Família: desafios para uma prática interdisciplinar [Dissertação de Mestrado]. São Paulo: Instituto de Psicologia, Universidade de São Paulo; 2013.

19 Paim JS, Travassos C, Almeida C, Bahia L, Macinko J. Saúde no Brasil 1. O sistema de saúde brasileiro: história, avanços e desafios. Lancet 2011; 6736:11-31

\section{Abstract}

The current study analyzed the conception and practice of matrix-based support among psychologists working at the Center for Family Health Support (NASF in Portuguese) in the city of São Paulo, Brazil. A qualitative methodology was used with semi-structured interviews that were taped, transcribed, and submitted to thematic content analysis. The study revealed dilemmas between the work as prescribed and what is possible to achieve in practice, and between idealization of the collaborative proposal and its implementation. Exchanges of knowledge and training appear as the principal meanings in the matrix-based concept. The practice revealed a complex context with heterogeneous work organization, lack of linkage between management levels and tensions in the execution of shared work, such as unequal division of tasks, in with the family health teams take responsibility for direct care to the population, while the NASF occupies the role of training and supervising, thereby generating conflicts over responsibility for care and creating a context which is hardly conducive to comprehensive, shared, and collaborative care.

Primary Health Care; Psychology; Mental Health; Patient Care Team
20. Giovanella L, Mendonça MHM. Atenção primária à saúde. In: Giovanella L, Escorel S, Lobato LVC, Noronha JC, Carvalho AI, organizadores. Políticas e sistemas de saúde no Brasil. 2a Ed. Rio de Janeiro: Editora Fiocruz; 2012. p. 493-545.

21. Peduzzi M. Equipe multiprofissional de saúde: conceito e tipologia. Rev Saúde Pública 2001; 35:103-9.

22. Testa M. Pensar em saúde. Porto Alegre: Editora Artes Médicas; 1992.

23. Azevedo NS, Kind L. Psicologia nos Núcleos de Apoio à Saúde da Família em Belo Horizonte. Psicol Ciênc Prof 2013; 33:520-35.

\section{Resumen}

El presente estudio analizó la concepción y la práctica de la organización matricial realizadas por psicólogos que trabajan en el Núcleo de Apoyo a la Salud de la Familia (NASF) en el Municipio de Sao Paulo, Brasil. Se utilizó metodología cualitativa, se realizaron entrevistas semiestructuradas, grabadas y transcritas, sometidas al análisis de contenido del tipo de temática. Esta investigación demuestra dilemas entre la prescripción del trabajo y lo que es posible ser realizado en la práctica, y entre la idealización de la propuesta colaborativa y su implantación. El intercambio de saberes y la capacitación aparecieron como los principales significados de la concepción de organización matricial. La práctica reveló un contexto complejo con una organización de trabajo bastante heterogénea, con falta de articulación entre equipos gerentes $y$ tensiones en la ejecución del trabajo compartido, como una división desigual de tareas, donde los equipos de salud de la familia deben responsabilizarse por la asistencia directa a la población, mientras el NASF ocupa el lugar de aquel que capacita y supervisa, generando conflictos sobre de quién es la responsabilidad de la asistencia, constituyendo un contexto poco propicio al cuidado integral, compartido y colaborativo.

Atención Primaria de Salud; Psicología; Salud Mental; Grupo de Atención al Paciente

Recebido em 29/Set/2015

Versão final reapresentada em 23/Mar/2016

Aprovado em 06/Abr/2016 